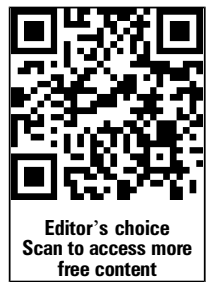

free content
${ }^{1}$ Department of Surgery, Sikkim Manipal Institute of Medical Sciences, Gangtok, Sikkim, India

${ }^{2}$ Department of Radiodiagnosis, Sikkim Manipal Institute of Medical Sciences, Gangtok, Sikkim, India

${ }^{3}$ Department of Pathology, Sikkim Manipal Institute of Medical Sciences, Gangtok, Sikkim, India

\section{Correspondence to} Dr Varun Kumar Singh, varunsingh.vks@gmail.com

Accepted 16 April 2014

\title{
A weeping umbilical hernia: bilateral ovarian mucinous cystadenoma with disseminated peritoneal adenomucinosis
}

\author{
Varun Kumar Singh, ${ }^{1}$ Kumar Nishant, ${ }^{1}$ Barun Kumar Sharma, ${ }^{2}$ Rachna Lamichaney ${ }^{3}$
}

\section{SUMMARY}

A young woman was referred to us for the management of an umbilical hernia with macerated overlying skin through which massive ascites was leaking. On examination we found a jelly-like substance seeping out of the opening. A contrast-enhanced CT scan of the abdomen revealed bilateral ovarian cystadenocarcinoma with pseudomyxoma peritonei. The patient underwent cytoreductive surgery along with hysterectomy and bilateral oophorectomy followed by hyperthermic intraperitoneal chemotherapy with mitomycin C. Histopathological examination showed bilateral borderline cystadenoma with peritoneal adenomucinosis. Follow-up at 1 year showed no signs of recurrence.

\section{BACKGROUND}

Pseudomyxoma peritonei is rarely encountered in day-to-day practice and is poorly understood. Most cases usually present as either an appendicular or ovarian pathology. Presentation as umbilical and bilateral inguinal hernias is rare.

\section{CASE PRESENTATION}

A young female patient aged 26 years from a very poor socio-economic background was referred to us for investigation and management of massive ascites which had eroded through a pre-existing umbilical hernia. A thorough history revealed a gradually distending abdomen initially, followed by a rapid increase in the size of the abdomen over the previous 6 months. The patient only visited the hospital when the umbilical hernia ruptured and started leaking. She also complained of a constant dull ache in her abdomen which had never upset her enough to visit hospital. She had no other abdominal complaints other than early satiety for the previous 6 months. She had achieved menarche at the age of 15 years and her menstrual cycles were normal in terms of duration and flow. She was married for almost a year and had no children. There were no other gynaecological complaints. Examination of the abdomen was remarkable as it was hugely distended and firm, and there was palpable nodularity all over the abdomen with a striking dull note in addition to liver dullness with no shifting dullness or fluid thrill. Bowel sounds were normal. There was an umbilical hernia which was perforated and weeping constantly. On close examination we found a jelly-like substance protruding from the perforation site. The patient also had bilateral inguinal herniae (figure 1). A working diagnosis of pseudomyxoma peritonei was made.

\section{INVESTIGATIONS}

The patient's haemoglobin was $6 \mathrm{~g} / \mathrm{dL}$ and total leukocyte count was $5600 / \mathrm{mm}^{3}$ of blood with a lymphocyte count of $58 \%$. Serum creatinine and blood urea were 1.7 and $78 \mathrm{mg} / \mathrm{dL}$, respectively. The urine examination was unremarkable and a chest X-ray did not reveal any abnormality except a markedly elevated diaphragm, which was consistent with the clinical examination.

Ultrasonography (figure 2) and a contrast-enhanced CT scan (figure 3A, B) of the abdomen revealed bilateral adnexal multiloculated cystic space-occupying lesions, a thickened omentum with multiple small cystic lesions and multiloculated intraperitoneal collections causing compression of the liver, pancreas and spleen resulting in a scalloped margin along with the umbilical hernia. Features were suggestive of bilateral ovarian cystadenoma or cystadenocarcinoma with pseudomyxoma peritonei.

\section{TREATMENT}

The patient was supported with packed cell transfusions and parenteral nutrition, before cytoreductive surgery was carried out. Intraoperative findings included cysts of varying sizes filled with mucoid and gelatinous material filling the entire peritoneal

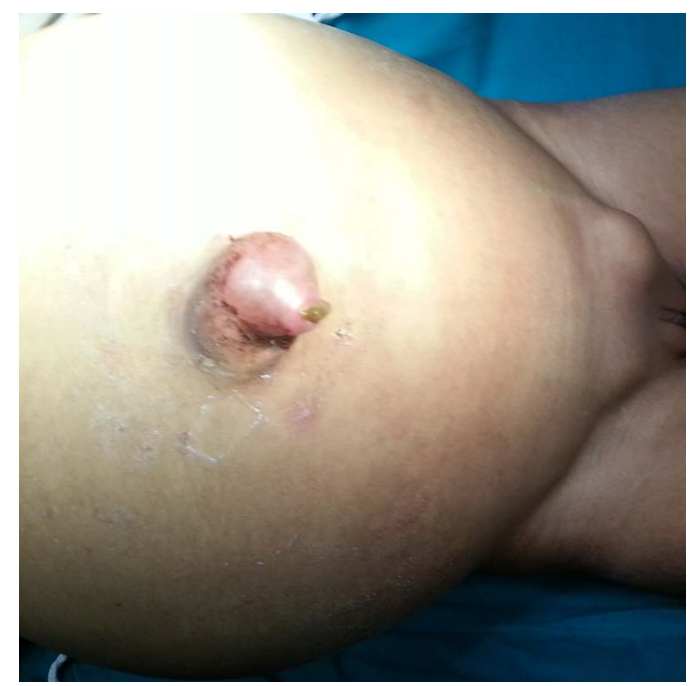

Figure 1 Pseudomyxoma peritonei with umbilical hernia with leaking gelatin-like fluid. Note the inguinal herniae. 


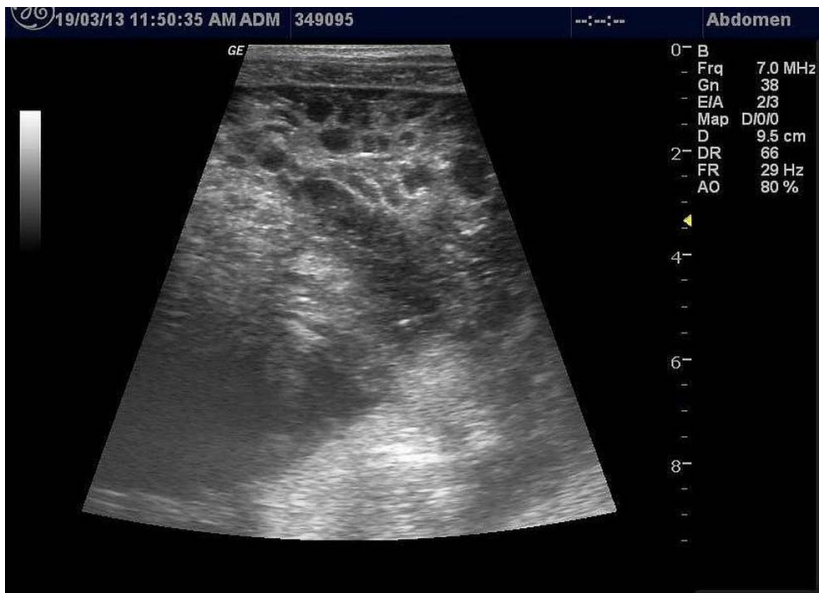

Figure 2 Ultrasound showing multiloculated intraperitoneal collections.
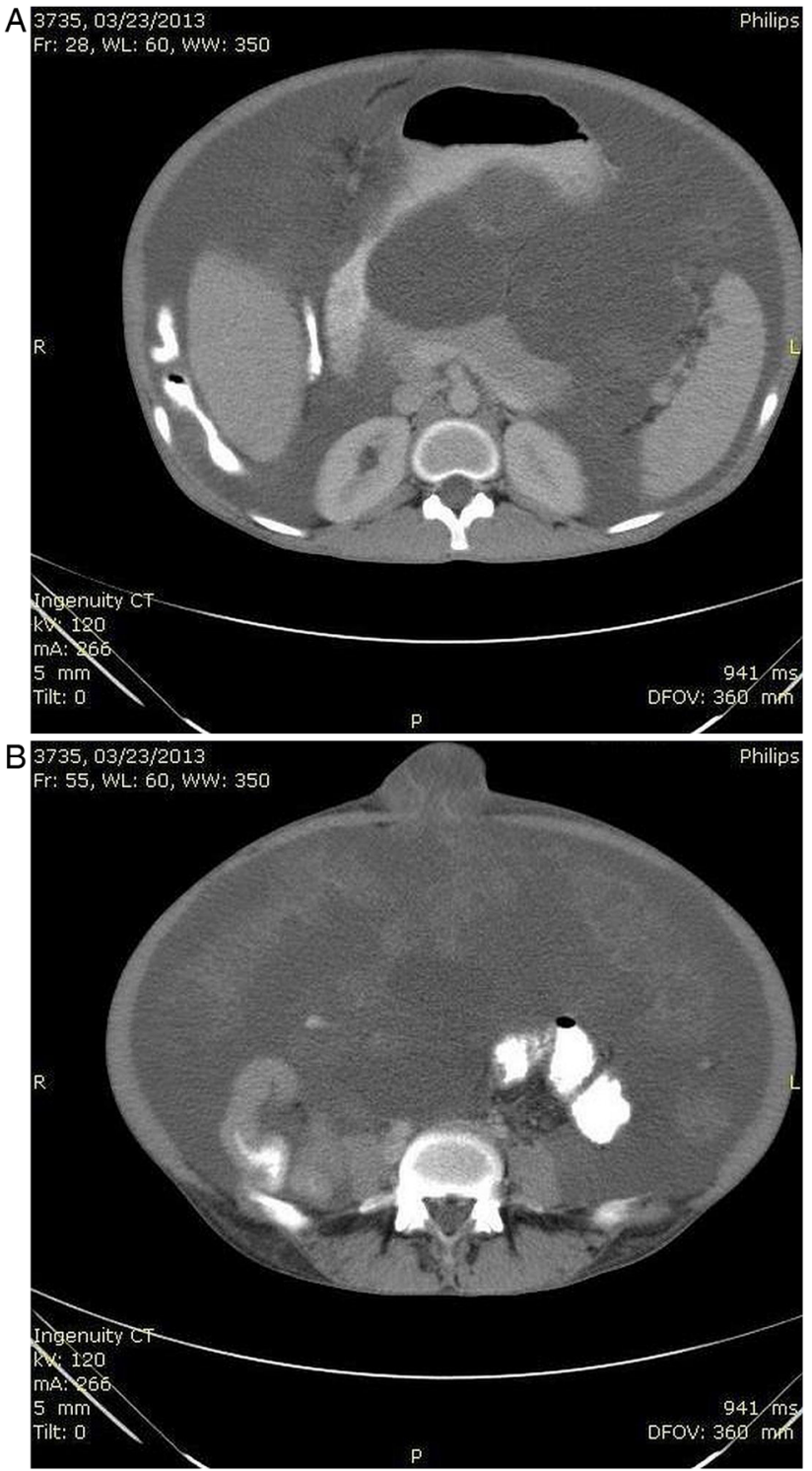

Figure 3 (A) Contrast-enhanced CT scan (CECT) of the abdomen showing a multiloculated cystic space-occupying lesion with thickened omentum and multiloculated intraperitoneal collections causing compression of the liver, pancreas and spleen leading to scalloped margins. (B) CECT showing multiloculated small cystic tissue protruding through the umbilical hernia. cavity (figure 4A,B). Both ovaries were enlarged and cystic, and filled with similar material (figure 5). However, the most interesting finding was that the appendix could not be located. Surgery consisted of total omentectomy, right and left parietal peritonectomy, pelvic peritonectomy, hysterectomy and bilateral salpingo-oophorectomy, lesser omentectomy and stripping of the visceral peritoneum. As much diseased tissue as possible was removed. This surgery was followed immediately by hyperthermic $\left(42.5^{\circ} \mathrm{C}\right)$ infusion of mitomycin $\mathrm{C}$, which was followed by 5 -fluorouracil infusion for 5 days. The patient was discharged after 10 days of uneventful post-operative recovery.

\section{OUTCOME AND FOLLOW-UP}

Histopathological examination of both ovaries showed multiple cysts lined with mucin-secreting columnar cells and at places stratification (two to three layers) and mild nuclear atypia suggesting borderline cystadenomas involving both ovaries (figure 6). Random sections from the omental mass showed a predominance of acellular mucinous material and strips of epithelium composed of mucin-secreting columnar cells with stratification, mild nuclear atypia and intracellular mucin in some places. Sections from the omphalocele showed normal-looking stratified squamous epithelium. The subepithelial zone showed fibrocollagenous tissue admixed with mucinous material and strips of epithelium lined by mucinous cells.

\section{DISCUSSION}

Pseudomyxoma peritonei, a term first used by Werth ${ }^{1}$ that actually means false tumour of the peritoneum, usually has its origins in an appendiceal adenocarcinoma or ovarian

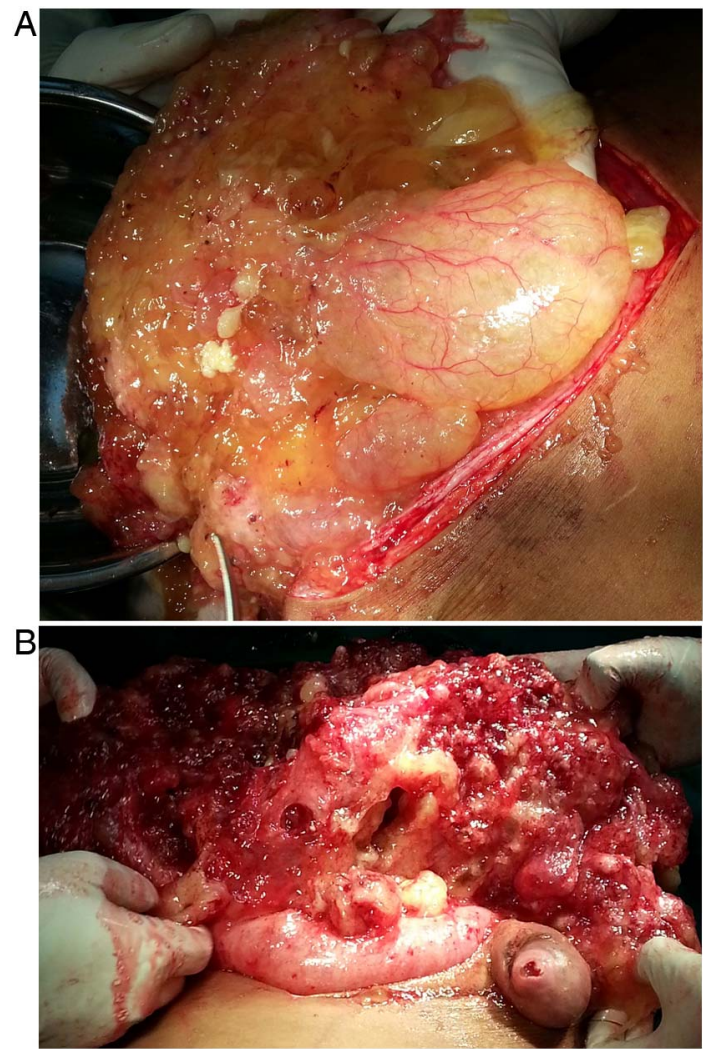

Figure 4 (A) Initial intraoperative view showing gelatinous tumour deposits in the omentum. (B) Intraoperative view showing gelatinous tumour deposits in the omentum and visceral peritoneum of the intestines. 


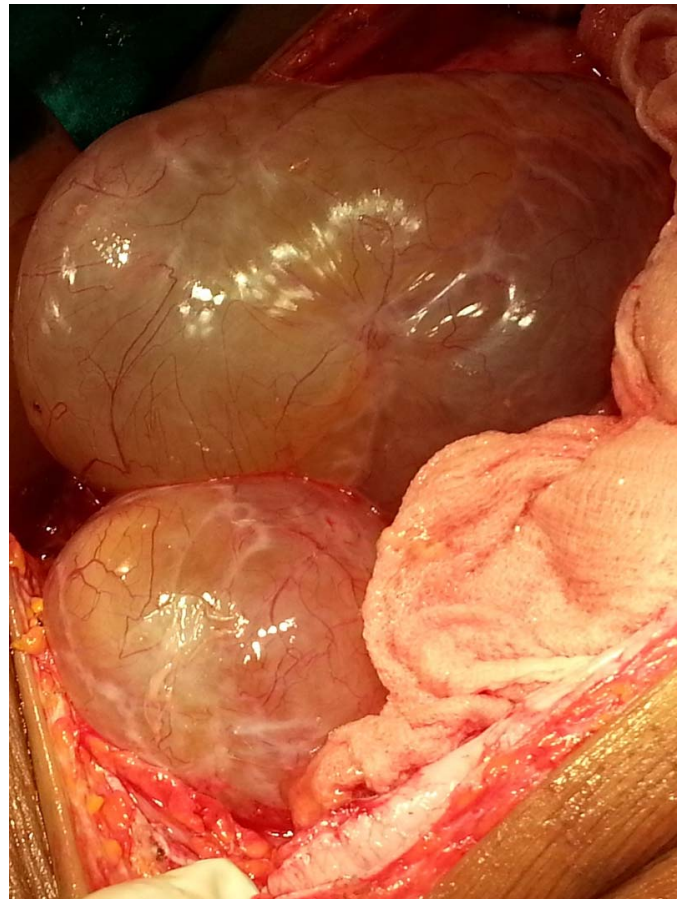

Figure 5 Intraoperative view following omentectomy, showing bilaterally enlarged cystic ovaries filled with gelatinous material.

cystadenoma, although other sites have also been described. ${ }^{2} 3$ It is a progressive disease and mostly affects women in their fifth to sixth decades. The earlier suggestion of a common ovarian origin is now debated and it has been proposed that women may have synchronous involvement of the appendix and ovary, with ovaries being secondarily involved following appendix rupture due to an enlarging mucinous adenocarcinoma. ${ }^{4}$ Clinical presentation varies and usually starts with non-specific symptoms which may include unexplained weight loss quickly followed by abdominal distension and pain. The most common presentation which prompts patient to present to hospital is features of appendicitis (27\%) followed by increased abdominal girth (23\%). Presentation as an ovarian mass $(20 \%)$ is the third

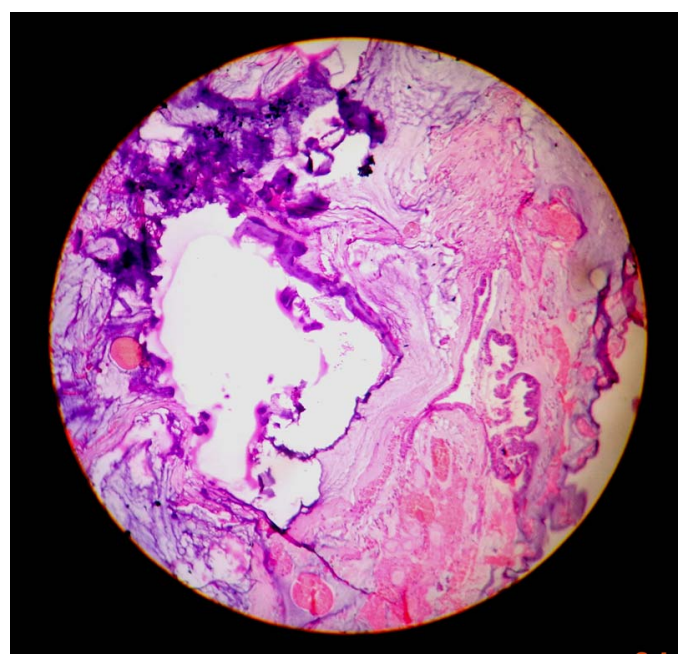

Figure 6 Mucin-secreting columnar cells lining the cyst wall. In places the lining shows stratification (two to three layers) and mild nuclear atypia. most common followed by hernia (14\%). ${ }^{5}$ Various other rare presentation have also been reported including recurrent incisional hernia. ${ }^{6} 7$

A classification was proposed on the basis of histopathology, and grouped patients into disseminated peritoneal adenomucinosis (DPAM), peritoneal mucinous carcinomatosis (PMCA) and PMCA with intermediate or discordant features (PMCA-I/D). DPAM has a far better prognosis than the other two conditions. ${ }^{8}$ Various prognostic factors were proposed including the presence of epithelial cells, but it was later found that virtually all cases of pseudomyxoma peritonei demonstrate some epithelial cells. Prognosis depends on the nature of the primary tumour and histological appearance. Completeness of cytoreduction therapy is a strong determinant of prognosis which is more likely achievable in DPAM. ${ }^{9} 10$

The treatment strategy has moved from multiple surgeries aimed at debulking and palliation to a more aggressive approach involving peritonectomy and perioperative chemotherapy intended for cure. ${ }^{11} 12$ The technique of peritonectomy involves greater omentectomy and right parietal peritonectomy with or without right colon resection, pelvic peritonectomy with or without sigmoid colon resection as well as hysterectomy and bilateral salpingo-oophorectomy, lesser omentectomy and dissection of the hepato-duodenal ligament with or without antrectomy and cholecystectomy, right upper quadrant peritonectomy and Glissonian capsule resection, left upper quadrant peritonectomy and left parietal peritonectomy with or without splenectomy and other intestinal resection and/or abdominal wall resection. Intraperitoneal chemotherapy is indicated to eradicate microscopic disease. Intraperitoneal chemotherapy is combined with hyperthermia (hyperthermic intraperitoneal chemotherapy, HIPEC). The intraperitoneal temperature is maintained at $42.5^{\circ}$ C. Commonly used drugs are cisplatin, mitomycin C, doxorubicin and 5-fluorouracil. In earlier series, the recurrence rate was reported to be high but this decreased considerably after the introduction of heated chemotherapy, and prognosis has improved over the years to reach a 5 -year survival rate of more than $80 \% .^{13} 14$

\section{Learning points}

- Pseudomyxoma peritonei is a relatively uncommon presentation of appendiceal adenocarcinoma or ovarian cystadenoma.

- Presentation as hernia is even more rare and can include virtually any type of ventral hernia.

- Unexplained weight loss followed by massive abdominal distension must be thoroughly investigated.

- Early detection followed by combined modality treatment with cytoreductive surgery and hyperthermic intraperitoneal chemotherapy can help achieve 5-year survival.

Contributors KN and VKS were clinically associated with the patient and performed the surgery. BKS carried out the radiological investigation and RL performed the histopathological examination. All the authors actively participated in drafting the manuscript.

Competing interests None.

Patient consent Obtained.

Provenance and peer review Not commissioned; externally peer reviewed. 


\section{REFERENCES}

1 Little JM, Halliday JP, Glenn DC. Pseudomyxoma peritonei. Lancet 1969;2:659-63.

2 Lang $\mathrm{H}$, Jahne J, Flemming P. Pseudomyxoma peritonei of appendiceal origin-a report of seven cases and a review of published reports. Eur J Surg 1995:161:355-60.

3 Limber GK, King RE, Silverberg SG. Pseudomyxoma peritonei. Ann Surg 1973:178:587-93.

4 Ronnett BM, Shmookler BM, Diener-West M, et al. Immunohistochemical evidence supporting the appendiceal origin of pseudomyxoma peritonei in women. Int J Gynecol Pathol 1997;16:1-9.

5 Esquivel J, Sugarbaker PH. Clinical presentation of the pseudomyxoma peritonei syndrome. Br J Surg 2000;87:1414-18.

6 Zanardi F. Pseudomyxoma peritonaei at the involucrum of a postlaparotomy hernia. Minerva Chirurgia 1951;6:435-40.

7 Ergul Z, Olcucuoglu E, Kulacoglu $H$, et al. Recurrent incisional hernia due to pseudomyxoma peritonei. Case Rep Med 2011;2011:853906.

8 Ronnett BM, Zahn CM, Kurman RJ, et al. Disseminated peritoneal adenomucinosis and peritoneal mucinous carcinomatosis. A clinicopathologic analysis of 109 cases with emphasis on distinguishing pathologic features, site of origin, prognosis, and relationship to "pseudomyxoma peritonei". Am J Surg Pathol 1995;

19:1390-408.

9 Young RH, Gilks CB, Scully RE. Mucinous tumors of the appendix associated with mucinous tumors of the ovary and pseudomyxoma peritonei. A clinicopathological analysis of 22 cases supporting an origin in the appendix. Am J Surg Pathol 1991;15:415-29.

10 Higa E, Rosai J, Pizzimbono CA, et al. Mucosal hyperplasia, mucinous cystadenoma, and mucinous cystadenocarcinoma of the appendix. A re-evaluation of appendiceal "mucocele". Cancer 1973;32:1525-41.

11 Sugarbaker PH. Peritonectomy procedures. Ann Surg 1995;221:29-42.

12 Sugarbaker $\mathrm{PH}$, Chang D. Results of treatment of 385 patients with peritoneal surface spread of appendiceal malignancy. Ann Surg Oncol 1999;6:727-31.

13 Sugarbaker $\mathrm{PH}$, Schmookler B, Ronnett BM, et al. Pseudomyxoma peritonei. $\mathrm{Br} J$ Surg 1999;86:842.

14 Witkamp AJ, de Bree E, Kaag MM, et al. Extensive surgical cytoreduction and intraoperative hyperthermic intraperitoneal chemotherapy in patients with pseudomyxoma peritonei. Br J Surg 2001;88:458-63.

Copyright 2014 BMJ Publishing Group. All rights reserved. For permission to reuse any of this content visit http://group.bmj.com/group/rights-licensing/permissions.

BMJ Case Report Fellows may re-use this article for personal use and teaching without any further permission.

Become a Fellow of BMJ Case Reports today and you can:

- Submit as many cases as you like

- Enjoy fast sympathetic peer review and rapid publication of accepted articles

- Access all the published articles

- Re-use any of the published material for personal use and teaching without further permission

For information on Institutional Fellowships contact consortiasales@bmjgroup.com

Visit casereports.bmj.com for more articles like this and to become a Fellow 